\title{
Augmenting engineered T-cell strategies in solid cancers through epigenetic priming
}

Nielsen, Aaraby Y.; Ormhøj, Maria; Traynor, Sofie; Gjerstorff, Morten F.

Published in:

Cancer Immunology, Immunotherapy

Link to article, DOI:

$10.1007 / \mathrm{s} 00262-020-02661-1$

Publication date:

2020

Document Version

Peer reviewed version

Link back to DTU Orbit

Citation (APA):

Nielsen, A. Y., Ormhøj, M., Traynor, S., \& Gjerstorff, M. F. (2020). Augmenting engineered T-cell strategies in solid cancers through epigenetic priming. Cancer Immunology, Immunotherapy, 69, 2169-2178 .

https://doi.org/10.1007/s00262-020-02661-1

\section{General rights}

Copyright and moral rights for the publications made accessible in the public portal are retained by the authors and/or other copyright owners and it is a condition of accessing publications that users recognise and abide by the legal requirements associated with these rights.

- Users may download and print one copy of any publication from the public portal for the purpose of private study or research.

- You may not further distribute the material or use it for any profit-making activity or commercial gain

- You may freely distribute the URL identifying the publication in the public portal

If you believe that this document breaches copyright please contact us providing details, and we will remove access to the work immediately and investigate your claim. 


\section{Augmenting engineered T-cell strategies in solid cancers through epigenetic priming}

Aaraby Y. Nielsen ${ }^{1, \S}$, Maria Ormh $\varnothing j^{2, \S}$, Sofie Traynor ${ }^{1}$ and Morten F. Gjerstorff ${ }^{1,3,4, *}$

${ }^{1}$ Department of Cancer and Inflammation Research, Institute of Molecular Medicine, University of Southern Denmark, Odense, Denmark

${ }^{2}$ Department of Health Technology, Technical University of Denmark, Lyngby, Denmark ${ }^{3}$ Department of Oncology, Odense University Hospital, Odense, Denmark

${ }^{4}$ Academy of Geriatric Cancer Research (AgeCare), Odense University Hospital, Odense, Denmark $\S^{\S}$ These authors contributed equally

*Corresponding author: mgjerstorff@health.sdu.dk 


\begin{abstract}
T-cell receptor (TCR)- and chimeric antigen receptor (CAR)-based adoptive cell transfer (ACT) has shown promising results in hematological malignancies, but remains immature in solid cancers. The challenges associated with identification of tumor-specific targets, the heterogenic antigen expression, limited T-cell trafficking to tumor sites and the hostile tumor microenvironment (TME), are all factors contributing to the limited efficacy of ACT therapies against solid tumors. Epigenetic priming of tumor cells and the microenvironment may be a way of overcoming these obstacles and improving the clinical efficacy of adoptive T-cell therapies in the future. Here, we review the current literature and suggest combining epigenetic modulators and ACT strategies as a way of augmenting the efficacy of TCR- and CAR-engineered T cells against solid tumors.
\end{abstract}

\title{
Précis
}

Treatment with inhibitors of epigenetic enzymes can change gene expression in solid tumors and potentially revert resistance to T-cell therapy. Here, we present data supporting combined treatment with epigenetic modulators and engineered T cells.

\section{Keywords}

Cancer immunotherapy; Genetically modified T cells; Solid tumors; Epigenetic drugs; Cancer/testis antigens; Combination therapy. 


\section{Background}

Discovering the ability of the immune system to recognize and eradicate tumor cells has, in recent years, revolutionized the treatment of patients with incurable cancers (1). These findings are now being leveraged to produce highly potent "living drugs" in the form of T-cell-based ACT products produced by expanding T cells from a patients' blood or tumor ex vivo and reinfusing them into the patient, where they have the potential to eliminate tumor cells. Tumor-infiltrating T cells (TILs) are expected to be largely tumor antigenspecific, and T-cell products derived from tumors depend on the repertoire of native TCRs for tumor cell recognition. Alternatively, T cells can be genetically modified during ex vivo culturing to express the $\alpha \beta$ chains of a TCR or a CAR $(2,3)$. In this way, T cells from patients can be redirected against a specific target antigen expressed on the tumor cells of the patient. CARs are fusion proteins composed of an extracellular targeting moiety, often derived from a monoclonal antibody, coupled to intracellular T-cell signaling domains (3). In the context of TCR-engineered T cells, the transgene consists of a synthetic $\alpha \beta$ TCR heterodimer. While CAR $T$ cells recognize antigens expressed on the surface of tumor cells independent of major histocompatibility complex (MHC), TCR-engineered T cells recognize both surface and intracellular antigens presented as peptide-MHC complexes on the target cell. Correspondingly, the repertoire size of potential CAR-targetable antigens is limited compared to TCR-targetable antigens, since only a fraction of potential targets is expressed on the surface of tumor cells. Despite this, the primary breakthrough in T-cell therapy has been the development of CAR T cells targeting the cardinal B-cell antigen, CD19. The clinical success of CD19-directed CAR T-cell therapy as treatment of several B-cell hematological malignancies recently led to the approval of Kymriah for relapsed/refractory $(r / r)$, acute lymphoblastic leukemia (ALL) and $r / r$ diffuse large B-cell lymphoma (DLBCL), and Yescarta for $r / r$ DLBCL and primary mediastinal B-cell lymphoma (PMBCL) by the US Food and Drug Administration (FDA) and European Medicines Agency (EMA) (1). Despite considerable effort, translating this initial success to solid tumors has been disappointing so far, and shown limited clinical efficacy. Recently, it has been proposed that epigenetic priming of both tumor cells and cells of the TME could have the potential to improve the clinical outcome of immunotherapy in the context of solid tumors $(4,5)$. Here, we review the current literature and suggest combining epigenetic modulators and ACT strategies as a way of augmenting the efficacy of TCR- and CAR-engineered T cells against solid tumors.

\section{Current limitations to the success of engineered T cells against solid tumors}

Several factors have been associated with the lack of efficacy of ACT strategies against solid tumors, including challenges identifying tumor-specific targets, heterogenic antigen expression in tumors, limited T-cell trafficking to tumor sites and a hostile TME.

\section{Challenges identifying tumor-specific antigens}


Identifying potential antigens for engineered T-cell strategies, which can be safely targeted without causing toxicity to healthy tissue due to cross-recognition (off-target toxicity) or low expression on normal tissue (ontarget/off-tumor toxicity), remains a major obstacle for the field $(6,7)$. Ideally, a potential target for T-cell therapy should be tumor-specific and ubiquitously expressed on all tumor cells, and with no expression on normal cells. In practice, the identification of such antigens is difficult, since most antigens are also expressed on healthy tissues. For hematological lineage markers, including CD19, expressed on normal and malignant B cells, such on-target/off-tumor toxicities are manageable. Infusion of CD19 CAR T cells also leads to killing of healthy B cells with resultant B-cell aplasia and hypogammaglobulinemia, but the resultant hypogammaglobulinemia can usually be managed with immunoglobulin substitution therapy (1). In contrast, targeting other antigens expressed in tumor and normal cells of solid tissues may have a fatal outcome. For solid tumors, different types of antigens, including neoantigens and tumor-associated antigens, have been exploited as targets for TCR or CAR T-cell therapy. Targeting each group of antigens has its own unique advantages and disadvantages.

Neoantigens, which arise from mutations leading to the production of immunogenic proteins, have been investigated as targets for both TCR and CAR T-cell therapy. Advantages of targeting neoantigens include their highly restricted expression pattern on tumor cells, thus increasing safety and limiting on-target/offtumor toxicity. However, neoantigens are primarily patient-specific, and their identification is a cumbersome process requiring both whole-exome and transcriptome sequencing of the patient tumor as well as custom generation of TCR- or CAR-modified T cells to match the molecular profile of the patient (2). Furthermore, epitope prediction may not always be straightforward. Despite the potentially time-consuming process of generating neoantigen-specific TCR-engineered T cells (8), several clinical trials have been conducted due to the large repertoire of TCR-targetable neoantigens with varying success. However, cross-reactivity caused by recognition of the corresponding wild-type peptide has been reported (2). Thus far, only one neoantigen has been successfully targeted by CAR T cells. Epidermal growth factor receptor variant III (EGFRvIII) is a neoantigen arising from mutations in the wild-type EGF receptor (EGFR), which generates a truncated constitutively active and ligand-independent version of the protein. Since EGFRvIll is expressed on the surface of $30 \%$ glioblastoma multiforme (GBM) cases, it has been investigated as a target for CAR T-cell therapy (9). Because CAR T cells are not restricted by HLA type, anti-EGFRvIII CAR T cells can be manufactured and administered to patients with this neoantigen on their tumor across HLA types within a short timeframe.

The difficulty of identifying tumor-specific antigens in solid tumors has led to the exploration of tumorassociated antigens as targets for TCR and CAR T-cell therapy. Despite being highly expressed on tumor cells, tumor-associated antigens are also expressed at lower levels in healthy tissue, posing a risk of on-target/offtumor toxicity. This has been substantiated in a number of clinical trials for both TCR- and CAR-based 
therapies wherein patients have died due to cross-recognition of life-sustaining tissue $(6,7)$. Cancer/testis antigens (CTAs) is a specific subgroup of tumor-associated antigens and perhaps the most promising group of targets for engineered T cells due to their restricted expression in somatic normal tissues, re-expression in a variety of cancers and immunogenic nature (10). The expression of CTAs in normal tissue is predominantly limited to immune-privileged tissues and, in these cases, the CTAs can be considered tumorspecific antigens. However, it is worth noting that some CTAs demonstrate low expression in normal tissue other than immune-privileged tissues (11). Both TCR- and CAR-based strategies have been designed to target CTAs, but despite the largely restricted nature of CTAs, cross-recognition of peptides and MHC has been demonstrated for affinity-enhanced TCR-engineered T cells and MHC-restricted antibody-based CAR T cells $(6,12)$. Reducing the affinity of the engineered cells may lower the potential risk of on-target/off-tumor toxicity but this can, in contrast, result in reduced cytotoxic efficacy against tumor cells.

\section{Challenges with antigen heterogeneity and immune escape}

Several cases of disease relapse due to antigen loss have been reported in the context of hematological malignancies, potentially as result of the selective pressure exerted by monospecific TCR- or CAR-engineered T-cell therapies $(13,14)$. With the heterogeneous nature of antigen expression in solid tumors, antigen escape variants are likely to be a preexisting hurdle for the curative potential of engineered T cells. Coexpressing multiple TCR sequences in a single T cell could potentially be one way of overcoming immune escape mechanisms. In the context of CAR T-cell therapy, several strategies relying on combinatorial antigen targeting to prevent the emergence of escape variants are now under development. For example, tandem CAR T cells have been developed to target multiple tumor antigens simultaneously. One such approach was used to target both HER2 and IL13R $\alpha 2$ in a murine model of GBM (15). In this model, HER2/IL13R $\alpha 2$ tandem CAR T cells could mitigate antigen escape and improve survival of mice compared to targeting HER2 or IL13Ra2 alone. Other approaches include design of bi- or tri-cistronic vectors allowing for expression of multiple CAR molecules with different specificities on the T-cell surface. Despite the potential usefulness of targeting multiple antigens simultaneously as a way of overcoming antigen-escape, identifying multiple antigens that can be safely targeted remains a major challenge for engineered T-cell strategies.

\section{Challenges with a hostile tumor microenvironment}

In addition to playing a notorious role in supporting tumor proliferation and progression, the TME also affects the activation and function of infiltrating $T$ cells (16). T-cell dysfunction in solid tumors is a result of multiple mechanisms, including upregulation of inhibitory checkpoint molecules, increased infiltration of inhibitory immune cells, and induction of an exhausted phenotype of infiltrating T cells, and is a major obstacle for the anti-tumor efficacy of engineered T cells. Checkpoint molecules have been demonstrated to be upregulated on tumor biopsies post-infusion of engineered T cells (9). This is supported by pre-clinical findings that 
combining engineered T-cell strategies with programmed cell death protein 1 (PD-1) pathway blockade can improve T-cell activity and promote tumor cell death (17). These results have provided a rationale for combining engineered T-cell strategies with checkpoint blockade to augment the clinical efficacy of engineered cells. Several subsets of inhibitory cells, including T regulatory cells (Tregs), M2-associated macrophages and myeloid-derived suppressor cells (MDSCs), can also be found in the TME and strongly effect the functionality of the infused product. For example, a clinical study utilizing CAR T cells targeting EGFRvIII in GBM demonstrated that clinical efficacy was hampered by increased infiltration of Tregs post CAR T-cell infusion (9). Several novel engineering strategies have been proposed to overcome the hostile microenvironment, including development of T cells redirected for antigen-unrestricted cytokine-initiated killing (TRUCKs), which can deliver a transgenic payload to polarize the microenvironment and enhance Tcell cytotoxicity or co-expression of dominant negative TGF $\beta$ receptor to counteract the inhibitory effects of TGF $\beta$ signaling (18).

\section{Epigenetic priming can augment T-cell immunotherapy}

Despite promising reports of objective responses noted in some patients, the majority of clinical trials with T-cell therapy against solid tumors have shown limited clinical efficacy. This is likely multifactorial and includes lack of safe targets, antigen heterogeneity leading to disease relapse with antigen-negative tumors, and an immunosuppressive TME. Epigenetic modulators can potentially augment T-cell therapies through multiple mechanisms, including upregulation of CTAs on tumors that limit antigen-heterogeneity and immune-escape, modulation of the TME to ensure improved T-cell trafficking to tumor sites, and enhanced T-cell efficacy and persistence, Figure 1.

\section{The epigenome of tumors}

It has long been acknowledged that cancer is a genetic disease and, more recently, it has become clear that epigenetic aberrations also play a key role in tumor initiation, evolution and progression (19). Epigenetic modifications do not alter the DNA sequence, but instead modify both DNA and histones to regulate gene expression through DNA and chromatin accessibility. Cell type-specific gene expression arises from tight control of the chromatin template, where a multitude of chromatin-associated proteins and enzymes function in concert to establish and maintain distinct chromatin states. Epigenetic mechanisms are essential for normal development and maintenance of cellular phenotype, and aberrancies in this control mechanism can lead to a wide range of diseases. Genetic, metabolic or environmental stimuli can disrupt the homeostatic balance of chromatin to promote restrictive or permissive epigenetic landscapes that induce transcriptional changes. Most of these changes will be inconsequential, but some will become drivers of malignant cellular transformation. Most cancers are associated with extensive dysregulation of epigenetic enzymes, and epigenetic defects contribute to diverse aspects of cancer biology (20). 
The most important epigenetic aberrancy in cancer is changes in DNA methylation. DNA methylation is a stable, heritable epigenetic mechanism involved in long-term transcriptional silencing, X-chromosome inactivation, genomic imprinting and prevention of chromosomal instability by silencing repetitive elements and transposons, thus stabilizing cellular identity by maintaining gene expression patterns and genomic stability (21). The cancer epigenome is generally characterized by global hypomethylation and site-specific CPG island promoter hypermethylation, which lead to changes in transcription levels of genes implicated in tumor development (22). DNA methylation patterns are generated and maintained by DNA methyltransferases (DNMTs), and tumor cells are often associated with DNMT abnormalities, such as overexpression and/or somatic mutations, highlighting this family of enzymes as important epigenetic targets for cancer therapy (23). Covalent post-translational histone tail modifications provide complex celltype-specific patterns that play a key role in determining transcriptional status. Important regulatory histone modifications include acetylation, methylation and ubiquitination of lysine residues. Lysine acetylation is generally associated with transcriptional activation and is controlled by histone acetyl transferases (HATs) and histone deacetylases (HDACs) that work in concert to maintain appropriate acetylation levels throughout the genome. HDACs are often found upregulated in various hematological and solid cancers, and their overexpression is linked to advanced disease and poor prognosis (24).

The reversible nature of epigenetic aberrations provides a promising opportunity for therapeutic intervention, and epigenetic modulatory drugs are already being used for treatment of hematological cancers. Despite limited success with epigenetic drugs as mono-therapeutic agents against solid tumors, combined therapies involving epigenetic modifiers have shown promise for achieving synergistic anti-tumor effects. Epigenetic priming with an epigenetic agent induces transcriptional changes that can sensitize the tumor cells to subsequent treatment, and it has been shown to increase tumor cell sensitivity to chemotherapeutic drugs, promote anti-tumor effects of molecular targeting agents, and overcome cancer resistance to hormonal drugs (25). Importantly, a role for epigenetic drugs as epigenetic primers is emerging in cancer immunotherapy as a way of augmenting T-cell therapy.

\section{Enhancing target expression with epigenetic modulators}

As previously mentioned, CTAs represent promising targets for cancer immunotherapy due to their cancerspecific expression pattern and immunogenicity. Importantly, studies have shown that expression of many CTA genes can be induced or upregulated by epigenetic modulators, most importantly DNA methyltransferase inhibitors (DNMTi) through de-methylation of promoters and gene bodies $(26,27)$. The promoters and proximal introns of CTA genes are either CpG-rich or contain CpG islands that can undergo methylation and de-methylation to regulate their expression. In normal somatic tissue, these promoters are 
highly methylated, facilitating transcriptional silencing, whereas the promoters are de-methylated in male germ cells and many types of tumors, which leads to gene expression (28). Thus, epigenetic modulation represents an attractive approach to simultaneously upregulate CTA expression on tumor cells and decrease antigen-heterogeneity within the tumor tissue $(29,30)$. Importantly, the effect of these modulators seems to be largely tumor cell-specific (31), and can potentially limit the risk of on-target/off-tumor toxicity when combined with both CAR- and TCR-engineered T-cell strategies.

DNMTi are cytidine analogues that predominantly work through incorporation in the DNA during replication, forming a covalent bond between the DNA methyltransferase enzyme and the inhibitor that leads to the degradation of the enzyme, ultimately resulting in transcriptional activation. Currently, these inhibitors (azacitidine; AZA and decitabine; DAC) are FDA- and EMA-approved for the treatment of myelodysplastic syndrome (MDS), acute myeloid leukemia (AML) and chronic myelomonocytic leukemia (CMML) (32). Histone deacetylase inhibitors (HDACi) and histone methyltransferase inhibitors (HMTi) have also been demonstrated to play a role in epigenetic regulation of CTA genes (10). Both groups of inhibitors modify the $\mathrm{N}$-terminal tail of histones, and while HDACs deacetylates lysine residues, HMTs methylates specific arginine and lysine residues, both leading to chromatin condensation and limited access of transcription factors (33). While the effect of HDACi alone results in modest CTA expression, combination therapy with both HDACi and DNMTi has been found to synergistically enhance CTA expression in tumors (34). Similarly, targeting HMT activity can also improve the effect of DNMTi on CTA expression (35) and, interestingly, the triple combination of DNMTi, HDACi and HMTi had a synergistic effect on expression of GAGE CTAs compared to double or single combinations (36). These results suggest that combining histone modulators, such as HDACi and HMTi, with DNMTi is likely to exert a more profound effect on CTA expression compared to a single agent.

Additionally, it has been shown that DNMTi therapy can lead to upregulation of viral tumor antigens, which can be targeted by T-cell therapy. Human endogenous retroviruses (HERVs) have been integrated in the genome as a consequence of retroviral infection of germ line cells during evolution and constitute $8 \%$ of the human genome. There are multiple families of HERVs, with more than one hundred copy numbers for some families (37). While most ERV genes are non-coding, a few are able to produce functional proteins, like the HERV-K HML-2 family. Similar to CTAs, HERV expression is also suppressed in normal somatic cells by DNA methylation and, consequently, the loss of DNA methylation in various cancers has been shown to activate transcription of these genes, and DNMTi can induce promoter hypomethylation and induce ERV expression (37). Furthermore, ERV expression has been reported to induce both innate and adaptive immune responses. Collectively, these findings support the potential role of HERVs as targets in cancer immunotherapy (38). The combination of DNMTi and HDACi has a synergetic effect on the expression of HERVs in vitro (39), suggesting 
the rationale of combining different inhibitors to upregulate ERV expression as a means of augmenting engineered T-cell therapies targeting ERV antigens. Thus far, preclinical results with CAR-engineered T cells targeting HERV-K envelope protein have shown anti-tumor effects in a melanoma xenograft model (40).

\section{Enhancing antigen processing and presentation with epigenetic inhibitors}

In addition to antigen loss, tumors have evolved other mechanisms to avoid detection by the immune system. Most significantly, downregulation of MHC class I prevents T-cell recognition and results in poor anti-tumor efficacy of TCR-engineered T cells. Thus, antigen presentation through MHC class I is essential for the success of TCR-engineered ACT. The molecular alterations causing MHC class I loss are divided into two groups; (I) "soft" reversible changes, like epigenetic modifications, and (II) "hard" irreversible changes, which includes structural genetic changes such as loss of gene expression (41). Where the "soft" changes can be reversed with different cytokines or drugs, the "hard" changes cannot and the expression of MHC class I molecules will remain low. Numerous mechanisms exist for MHC class I downregulation or loss, including loss of expression or mutations in B2M or antigen processing machinery (APM) genes, leading to impaired MHC class I assembly, and hypermethylation of HLA genes resulting in repressed expression (42). Importantly, DNMTi and HDACi can restore antrigen presentation by enhancing transcription of genes encoding HLA and APM components, including TAP1/2 and tapasin (43). In line with this, biopsies from breast cancer patients treated with a combinatorial therapy of DNMTi and HDACi demonstrated increased expression of MHC class I compared to biopsies obtained prior to treatment (44), indicating that this treatment combination is indeed clinically relevant. The identification of such new strategies to reverse MHC downregulation is highly important in overcoming the loss of antigen presentation in solid tumors and increasing the efficacy of ACT strategies. As CARs recognize antigens in an HLA-independent manner, these obstacles are not present in these settings.

\section{Overcoming the immunosuppressive environment}

The involvement of the TME in ACT responses (as well as tumor progression) is of significant importance, and overcoming the immunosuppressive environment is a critical step in realizing the full potential of engineered ACT products against solid tumors. Epigenetic modulators have the ability to modulate the TME of solid cancers through various mechanisms in order to facilitate successful trafficking and sustained effector functions of T cells.

In addition to the potential role of HERVs as targets for ACT, DNMTi-induced ERV expression exhibits an antitumor effect through activation of type I or III interferon response $(45,46)$. DNMTis induce bidirectional transcription of HERVs, which leads to the formation of double-stranded RNA (dsRNA) molecules that activate pattern-recognition receptors, including MDA5 and RIG-I, both of which can detect viral dsRNA (of 
different lengths) in the cytoplasm of cells. This can lead to the nuclear translocation of multiple transcription factors, IRF3, IRF7 and NF-KB, in a MAVS-dependent manner. These transcription factors activate transcription of interferons. Interferon binding to the respective receptor leads to production of interferonstimulated genes (ISGs) through JAK/STAT signaling. The subsequent expression of ISGs induces antiproliferative and immunomodulatory genes and expression of various immune cell-attracting chemokines and cytokines. Similar to the above data, upregulation of immune genes by DNMTis is observed in vivo in patient biopsies from a broad range of solid tumor types (47). In line with this, the activaction of a type I interferon response in an preclinical ovarian cancer model, was shown to enhance CD8+ T-cell infiltration (48). In a similar model, DNMTi was also shown to facilitate T-cell entry into tumors through increased expression of the important T-cell chemokines CXCL9 and CXCL10 by direct promoter demethylation (49). Taken together, this suggests that DMNTi treatment could lead to tumor attraction of lymphocytes and augment ACT response.

Also the anti-tumor effector functions of T cells may be enhanced by DNMTi, especially through modulation of T-cell repressive cell types in the TME. DNMTi alone or in combination with HDACi was demonstrated to decrease the numbers of T-cell suppressive macrophages and MDSCs in the TME in several studies (44, 48, $50,51)$. In another study, the number of circulating and spleenic MDSCs were greatly reduced by DNMTi (52). The effect of DNMTi on Tregs remains controversial. DNMTi treatment has been demonstrated to hypomethylate and induced the transcription of FOXP3 (53), which encodes on important transcription factor for polarizing CD4+ T cells towards a Treg phenotype. However, in patients with myelodysplastic syndrome DNMTi was found to inhibit the proliferation and suppressive function of Tregs, despite the demethylation and increased expression of FOXP3 (54). Other types of epigenetic inhibitors have shown promiss in stimulating anti-tumor immunity by inhibiting the function of Tregs. For instance, inhibition of EZH2, the catalytic component of polycomb repressive complex 2, destabilized FOXP3 expression and reprogrammed Tregs towards a proinflammatory phenotype (55) and HDACi in combination with the bromodomain inhibitor JQ1 attenuated the function of Tregs in a NSCLC mouse model to support anti-tumor immunity (56). Thus, these results suggest that epigenetic modulation favors T-cell recruitment and reduce the immune suppressive state of the microenvironment. The direct effect of DNMTi on CD8+ T-cells has also been investigated in a number of studies, but while an anti-proliferative effect has been reported (57), DNMTi generally does not seem to affect the number and function of tumor-infiltrating CD8+ T-cells and may even rejuvenate these cells (58).

\section{Preclinical studies of the combination of epigenetic inhibitors and adoptive cell transfer (ACT)}

There are compelling indications that epigenetic therapy may change various phenotypes of the tumor and TME to enhance the effect of ACT and a number of preclinical studies support this (Table 2). For instance, 
lung metastasis of 4T1 murine breast cancer cells in syngeneic mice were effectively targeted with ACT after pre-treatment with DNMTi (59). The epigenetic priming induced the expression of the murine CTA P1A, which was subsequently targeted by P1A-specific cytotoxic T cells with synergistic effects. Similarly, the combined use of DNMTi and HDACi was demonstrated in vitro to enhance the expression and targeting of CTA MAGEC2 in human breast cancer cells by human T cells genetically engineered to express MAGE-C2-TCR (60). CTA NY-ESO-1 was targeted by a similar strategy in colorectal cancer and glioma with good results $(61,62)$. In both cases, the strategy was selective towards cancer cells leaving untransformed cells unharmed. In melanoma cells, the PRAME antigen could similarly be induced by DNMTi and targeted by PRAM-specific T cells (63).

HDACi may also be used alone to support ACT. Inhibition of HDAC activity with LAQ824 in mice carrying B16 melanoma tumors improved the anti-tumor effect of ACT with anti-gp100 T cells (64). The combination treatment greatly increased numbers of tumor infiltrating gp100-specific T cells and improved control of tumor growth. This was attributed to the increased expression of tumor-associated gp100 and MHC levels, as well as a direct effect on the functional activity of T cells. Recently, EZH2 inhibitors were also demonstrated to synergize with ACT. EZH2 was found to bind the promoters of genes encoding two enzymes important for the synthesis of ganglioside $G_{D 2}$ and $E Z H 2$ inhibition increased the expression of $G_{D 2}$ on the surface of Ewing sarcoma cells (65). This sensitized the sarcoma cells to killing by $G_{D 2}$-specific CAR T cells.

Importantly, these experiments, especially those involving fully immune competent mice, demonstrate the potential benefit and safety of combining epigenetic inhibitors with ACT. However, more data from preclinical models and clinical trials are needed to define the most suitable strategies for intervention.

\section{Clinical relevance}

Epigenetic priming can augment the clinical use of T-cell therapies for solid tumors through multiple mechanisms, including I) upregulation of CTAs on tumors, which are considered safe targets due to their restricted expression, II) decreasing antigen heterogeneity in tumors and thus hindering immune-escape, III) modulating the tumor microenvironment to enhance T-cell trafficking and survival after reaching the tumor, and IV) enhancing both T-cell anti-tumor activity and persistence, all of which are currently considered major obstacles for the curative potential of engineered T-cell strategies against solid tumors. Thus, combination therapy with epigenetic modulators and TCR- or CAR-based strategies represents a highly promising therapeutic strategy for immunotherapy of solid tumors. Patients with metastatic cancers may be treated with epigenetic drugs such as DNMT inhibitors ealy after diagnosis to precondition tumors to therapy with genetically modified T cells. Before DNMT inhibitor treatment blood is drawn to enable the expansion and genetic modification of patient T cells with TCRs that recognize one or multiple CTAs upregulated by DNMT 
inhibitors, such as MAGE-A or NY-ESO-1. In addition to induction of CTA expression, the DNMT inhibitor pretreatment may induce expression of chemokines and other cytokines that will attract genetically modified $\mathrm{T}$ cell to tumors upon infusion and produce a favorable tumor environtment to support anti-tumor $\mathrm{T}$ cell function. In principle, the combination of epigenetic modulators and TCR- or CAR-based strategies can be used for treatment of multiple cancer types in a broad range of patients, irrespectively of prior antigen status of the tumors. The clinical testing of this strategy this strategy should be of high priority to support the further implementation of T-cell therapy in treatment of solid tumors.

\section{Declarations}

Not relevant

\section{Funding}

This work was supported by the Velux Foundation, the Danish Cancer Society, the Academy of Geriatric Cancer Research (AgeCare), the Novo Nordisk Foundation, the Danish Research Council for Independent Research and the Danish Ministry of Health.

\section{Acknowledgments}

We thank M.K. Occhipinti for editorial assistance.

\section{Conflicts of Interest}

The authors declare no conflict of interest.

\section{Author contributions}

Morten Gjerstorff grafted the idea for the manuscript. All authors contributed to the literature search and data analysis. The first draft of the manuscript was written by Aaraby Nielsen, Maria Ormhøj and Sofie Traynor. All authors commented on previous versions of the manuscript. All authors read, critically revised the work and approved the final manuscript. 


\section{References}

1. Zheng PP, Kros JM, and Li J. Approved CAR T cell therapies: ice bucket challenges on glaring safety risks and long-term impacts. Drug Discov Today. 2018;23(6):1175-82.

2. Matsuda T, Leisegang M, Park JH, Ren L, Kato T, Ikeda Y, et al. Induction of Neoantigen-Specific Cytotoxic T Cells and Construction of T-cell Receptor-Engineered T Cells for Ovarian Cancer. Clin Cancer Res. 2018;24(21):5357-67.

3. Guedan S, Calderon H, Posey AD, Jr., and Maus MV. Engineering and Design of Chimeric Antigen Receptors. Mol Ther Methods Clin Dev. 2019;12:145-56.

4. Carter CA, Oronsky BT, Roswarski J, Oronsky AL, Oronsky N, Scicinski J, et al. No patient left behind: The promise of immune priming with epigenetic agents. Oncoimmunology. 2017;6(10):e1315486.

5. Jones PA, Ohtani $H$, Chakravarthy A, and De Carvalho DD. Epigenetic therapy in immuneoncology. Nat Rev Cancer. 2019;19(3):151-61.

6. Morgan RA, Chinnasamy N, Abate-Daga D, Gros A, Robbins PF, Zheng Z, et al. Cancer regression and neurological toxicity following anti-MAGE-A3 TCR gene therapy. J Immunother. 2013;36(2):133-51.

7. Morgan RA, Yang JC, Kitano M, Dudley ME, Laurencot CM, and Rosenberg SA. Case report of a serious adverse event following the administration of $T$ cells transduced with a chimeric antigen receptor recognizing ERBB2. Mol Ther. 2010;18(4):843-51.

8. Liu S, Matsuzaki J, Wei L, Tsuji T, Battaglia S, Hu Q, et al. Efficient identification of neoantigenspecific T-cell responses in advanced human ovarian cancer. J Immunother Cancer. 2019;7(1):156.

9. O'Rourke DM, Nasrallah MP, Desai A, Melenhorst JJ, Mansfield K, Morrissette JJD, et al. A single dose of peripherally infused EGFRvIII-directed CAR T cells mediates antigen loss and induces adaptive resistance in patients with recurrent glioblastoma. Sci Transl Med. 2017;9(399).

10. Gjerstorff MF, Andersen MH, and Ditzel HJ. Oncogenic cancer/testis antigens: prime candidates for immunotherapy. Oncotarget. 2015;6(18):15772-87.

11. Scanlan MJ, Simpson AJ, and Old LJ. The cancer/testis genes: review, standardization, and commentary. Cancer Immun. 2004;4:1.

12. Maus MV, Plotkin J, Jakka G, Stewart-Jones G, Riviere I, Merghoub T, et al. An MHC-restricted antibody-based chimeric antigen receptor requires TCR-like affinity to maintain antigen specificity. Mol Ther Oncolytics. 2016;3:1-9.

13. Sotillo E, Barrett DM, Black KL, Bagashev A, Oldridge D, Wu G, et al. Convergence of Acquired Mutations and Alternative Splicing of CD19 Enables Resistance to CART-19 Immunotherapy. Cancer Discov. 2015;5(12):1282-95.

14. Rapoport AP, Stadtmauer EA, Binder-Scholl GK, Goloubeva O, VogI DT, Lacey SF, et al. NY-ESO1-specific TCR-engineered T cells mediate sustained antigen-specific antitumor effects in myeloma. Nat Med. 2015;21(8):914-21.

15. Hegde M, Mukherjee M, Grada Z, Pignata A, Landi D, Navai SA, et al. Tandem CAR T cells targeting HER2 and IL13Ralpha2 mitigate tumor antigen escape. J Clin Invest. 2016;126(8):3036-52.

16. Massa C, and Seliger B. The tumor microenvironment: Thousand obstacles for effector T cells. Cell Immunol. 2019;343:103730.

17. John LB, Devaud C, Duong CP, Yong CS, Beavis PA, Haynes NM, et al. Anti-PD-1 antibody therapy potently enhances the eradication of established tumors by gene-modified T cells. Clin Cancer Res. 2013;19(20):5636-46.

18. Kloss CC, Lee J, Zhang A, Chen F, Melenhorst JJ, Lacey SF, et al. Dominant-Negative TGF-beta Receptor Enhances PSMA-Targeted Human CAR T Cell Proliferation And Augments Prostate Cancer Eradication. Mol Ther. 2018;26(7):1855-66.

19. Feinberg AP, Ohlsson R, and Henikoff S. The epigenetic progenitor origin of human cancer. Nat Rev Genet. 2006;7(1):21-33.

20. Chatterjee A, Rodger EJ, and Eccles MR. Epigenetic drivers of tumourigenesis and cancer metastasis. Semin Cancer Biol. 2018;51:149-59.

21. Jones PA, and Baylin SB. The fundamental role of epigenetic events in cancer. Nat Rev Genet. 2002;3(6):415-28. 
23. Rodriguez-Paredes $\mathrm{M}$, and Esteller M. Cancer epigenetics reaches mainstream oncology. Nat Med. 2011;17(3):330-9.

24. Li Y, and Seto E. HDACs and HDAC Inhibitors in Cancer Development and Therapy. Cold Spring Harb Perspect Med. 2016;6(10).

25. Cheng $\mathrm{Y}, \mathrm{He} \mathrm{C}$, Wang $\mathrm{M}, \mathrm{Ma} \mathrm{X}, \mathrm{Mo} \mathrm{F}$, Yang S, et al. Targeting epigenetic regulators for cancer therapy: mechanisms and advances in clinical trials. Signal Transduct Target Ther. 2019;4:62.

26. Sigalotti L, Fratta E, Coral S, Tanzarella S, Danielli R, Colizzi F, et al. Intratumor heterogeneity of cancer/testis antigens expression in human cutaneous melanoma is methylation-regulated and functionally reverted by 5-aza-2'-deoxycytidine. Cancer Res. 2004;64(24):9167-71.

27. Weber J, Salgaller M, Samid D, Johnson B, Herlyn M, Lassam N, et al. Expression of the MAGE1 tumor antigen is up-regulated by the demethylating agent 5-aza-2'-deoxycytidine. Cancer Res. 1994;54(7):1766-71.

28. Fratta E, Coral S, Covre A, Parisi G, Colizzi F, Danielli R, et al. The biology of cancer testis antigens: putative function, regulation and therapeutic potential. Mol Oncol. 2011;5(2):164-82.

29. Srivastava P, Paluch BE, Matsuzaki J, James SR, Collamat-Lai G, Taverna P, et al. Immunomodulatory action of the DNA methyltransferase inhibitor SGI-110 in epithelial ovarian cancer cells and xenografts. Epigenetics. 2015;10(3):237-46.

30. Heninger E, Krueger TE, Thiede SM, Sperger JM, Byers BL, Kircher MR, et al. Inducible expression of cancer-testis antigens in human prostate cancer. Oncotarget. 2016;7(51):84359-74.

31. Karpf AR, Lasek AW, Ririe TO, Hanks AN, Grossman D, and Jones DA. Limited gene activation in tumor and normal epithelial cells treated with the DNA methyltransferase inhibitor 5-aza-2'-deoxycytidine. Mol Pharmacol. 2004;65(1):18-27.

32. Wolff F, Leisch M, Greil R, Risch A, and Pleyer L. The double-edged sword of (re)expression of genes by hypomethylating agents: from viral mimicry to exploitation as priming agents for targeted immune checkpoint modulation. Cell Commun Signal. 2017;15(1):13.

33. Shahbazian MD, and Grunstein M. Functions of site-specific histone acetylation and deacetylation. Annu Rev Biochem. 2007;76:75-100.

34. Wischnewski F, Pantel K, and Schwarzenbach $\mathrm{H}$. Promoter demethylation and histone acetylation mediate gene expression of MAGE-A1, -A2, -A3, and -A12 in human cancer cells. Mol Cancer Res. 2006;4(5):339-49.

35. Link PA, Gangisetty O, James SR, Woloszynska-Read A, Tachibana M, Shinkai Y, et al. Distinct roles for histone methyltransferases G9a and GLP in cancer germ-line antigen gene regulation in human cancer cells and murine embryonic stem cells. Mol Cancer Res. 2009;7(6):851-62.

36. Sun F, Chan E, Wu Z, Yang X, Marquez VE, and Yu Q. Combinatorial pharmacologic approaches target EZH2-mediated gene repression in breast cancer cells. Mol Cancer Ther. 2009;8(12):3191-202.

37. Zhang $\mathrm{M}$, Liang $\mathrm{JQ}$, and Zheng $\mathrm{S}$. Expressional activation and functional roles of human endogenous retroviruses in cancers. Rev Med Virol. 2019;29(2):e2025.

38. Alcazer V, Bonaventura P, and Depil S. Human Endogenous Retroviruses (HERVs): Shaping the Innate Immune Response in Cancers. Cancers (Basel). 2020;12(3).

39. Daskalakis M, Brocks D, Sheng YH, Islam MS, Ressnerova A, Assenov $\mathrm{Y}$, et al. Reactivation of endogenous retroviral elements via treatment with DNMT- and HDAC-inhibitors. Cell Cycle. 2018;17(7):81122.

40. Krishnamurthy J, Rabinovich BA, Mi T, Switzer KC, Olivares S, Maiti SN, et al. Genetic Engineering of $\mathrm{T}$ Cells to Target HERV-K, an Ancient Retrovirus on Melanoma. Clin Cancer Res. 2015;21(14):3241-51.

41. Garrido F, Cabrera T, and Aptsiauri N. "Hard" and "soft" lesions underlying the HLA class I alterations in cancer cells: implications for immunotherapy. Int J Cancer. 2010;127(2):249-56.

42. $\quad$ Garrido F. MHC/HLA Class I Loss in Cancer Cells. Adv Exp Med Biol. 2019;1151:15-78.

43. Campoli $M$, and Ferrone S. HLA antigen changes in malignant cells: epigenetic mechanisms and biologic significance. Oncogene. 2008;27(45):5869-85. 

methyltransferase inhibition upregulates MHC-I to potentiate cytotoxic T lymphocyte responses in breast cancer. Nat Commun. 2018;9(1):248.

45. Chiappinelli KB, Strissel PL, Desrichard A, Li H, Henke C, Akman B, et al. Inhibiting DNA Methylation Causes an Interferon Response in Cancer via dsRNA Including Endogenous Retroviruses. Cell. 2015;162(5):974-86.

46. Roulois D, Loo Yau H, Singhania R, Wang Y, Danesh A, Shen SY, et al. DNA-Demethylating Agents Target Colorectal Cancer Cells by Inducing Viral Mimicry by Endogenous Transcripts. Cell. 2015;162(5):961-73.

47. Li H, Chiappinelli KB, Guzzetta AA, Easwaran H, Yen RW, Vatapalli R, et al. Immune regulation by low doses of the DNA methyltransferase inhibitor 5-azacitidine in common human epithelial cancers. Oncotarget. 2014;5(3):587-98.

48. Stone ML, Chiappinelli KB, Li H, Murphy LM, Travers ME, Topper MJ, et al. Epigenetic therapy activates type $I$ interferon signaling in murine ovarian cancer to reduce immunosuppression and tumor burden. Proc Natl Acad Sci U S A. 2017;114(51):E10981-E90.

49. Peng D, Kryczek I, Nagarsheth N, Zhao L, Wei S, Wang W, et al. Epigenetic silencing of TH1type chemokines shapes tumour immunity and immunotherapy. Nature. 2015;527(7577):249-53.

50. Kim K, Skora AD, Li Z, Liu Q, Tam AJ, Blosser RL, et al. Eradication of metastatic mouse cancers resistant to immune checkpoint blockade by suppression of myeloid-derived cells. Proc Natl Acad Sci U S A. 2014;111(32):11774-9.

51. Zhou J, Yao Y, Shen Q, Li G, Hu L, and Zhang X. Demethylating agent decitabine disrupts tumorinduced immune tolerance by depleting myeloid-derived suppressor cells. J Cancer Res Clin Oncol. 2017;143(8):1371-80.

52. Terracina KP, Graham L, Payne KK, Manjili MH, Baek A, Damle SR, et al. DNA methyltransferase inhibition increases efficacy of adoptive cellular immunotherapy of murine breast cancer. Cancer Immunol Immunother. 2016;65(9):1061-73.

53. Lal G, Zhang N, van der Touw W, Ding Y, Ju W, Bottinger EP, et al. Epigenetic regulation of Foxp3 expression in regulatory T cells by DNA methylation. J Immunol. 2009;182(1):259-73.

54. $\quad$ Costantini B, Kordasti SY, Kulasekararaj AG, Jiang J, Seidl T, Abellan PP, et al. The effects of 5azacytidine on the function and number of regulatory $T$ cells and T-effectors in myelodysplastic syndrome. Haematologica. 2013;98(8):1196-205.

55. Wang D, Quiros J, Mahuron K, Pai CC, Ranzani V, Young A, et al. Targeting EZH2 Reprograms Intratumoral Regulatory T Cells to Enhance Cancer Immunity. Cell Rep. 2018;23(11):3262-74.

56. Adeegbe DO, Liu Y, Lizotte PH, Kamihara $Y$, Aref AR, Almonte $C$, et al. Synergistic Immunostimulatory Effects and Therapeutic Benefit of Combined Histone Deacetylase and Bromodomain Inhibition in Non-Small Cell Lung Cancer. Cancer Discov. 2017;7(8):852-67.

57. Stubig T, Badbaran A, Luetkens T, Hildebrandt Y, Atanackovic D, Binder TM, et al. 5-azacytidine promotes an inhibitory T-cell phenotype and impairs immune mediated antileukemic activity. Mediators Inflamm. 2014;2014:418292.

58. Ghoneim HE, Fan Y, Moustaki A, Abdelsamed HA, Dash P, Dogra P, et al. De Novo Epigenetic Programs Inhibit PD-1 Blockade-Mediated T Cell Rejuvenation. Cell. 2017;170(1):142-57 e19.

59. Guo ZS, Hong JA, Irvine KR, Chen GA, Spiess PJ, Liu Y, et al. De novo induction of a cancer/testis antigen by 5-aza-2'-deoxycytidine augments adoptive immunotherapy in a murine tumor model. Cancer Res. 2006;66(2):1105-13.

60. Kunert A, van Brakel M, van Steenbergen-Langeveld S, da Silva M, Coulie PG, Lamers C, et al. MAGE-C2-Specific TCRs Combined with Epigenetic Drug-Enhanced Antigenicity Yield Robust and TumorSelective T Cell Responses. J Immunol. 2016;197(6):2541-52.

61. Chou J, Voong LN, Mortales CL, Towlerton AM, Pollack SM, Chen X, et al. Epigenetic modulation to enable antigen-specific T-cell therapy of colorectal cancer. J Immunother. 2012;35(2):131-41.

62. Natsume A, Wakabayashi T, Tsujimura K, Shimato S, Ito M, Kuzushima K, et al. The DNA demethylating agent 5-aza-2'-deoxycytidine activates NY-ESO-1 antigenicity in orthotopic human glioma. Int J Cancer. 2008;122(11):2542-53. 
63.

Yan M, Himoudi N, Basu BP, Wallace R, Poon E, Adams S, et al. Increased PRAME antigenspecific killing of malignant cell lines by low avidity CTL clones, following treatment with 5-Aza-2'Deoxycytidine. Cancer Immunol Immunother. 2011;60(9):1243-55.

64.

Vo DD, Prins RM, Begley JL, Donahue TR, Morris LF, Bruhn KW, et al. Enhanced antitumor activity induced by adoptive T-cell transfer and adjunctive use of the histone deacetylase inhibitor LAQ824. Cancer Res. 2009;69(22):8693-9.

65. Kailayangiri S, Altvater B, Lesch S, Balbach S, Gottlich C, Kuhnemundt J, et al. EZH2 Inhibition in Ewing Sarcoma Upregulates GD2 Expression for Targeting with Gene-Modified T Cells. Mol Ther. 2019;27(5):933-46. 
Figure 1. DNMT inhibitors support anti-tumor T-cell immunity through multiple mechanisms. DNMT inhibitors are among the most studied type of epigenetic drugs and their effects on tumor cells are well characterized. The depletion of DNMTs from tumor cells leads to extensive DNA hypomethylation and enhanced expression of hundres of genes, including tumor antigens (i.e. CTAs and HERVs) and key components of the antigen processing and presentation pathways (e.g. HLA I). The induction of HERV RNA species further provokes a viral-mimicry response that triggers the production of multiple immune signaling molecules, including type I interferons and other cytokines and chemokines with autocrine and paracrine effects on tumor and immune cells. DNMT inhibitors also exert indirect effects on the tumor by reducing the presence of TAMs and MDSCs. The net result of these effects should be a TME that better supports antitumor T cell immunity, which advocates the combined use epigenetic drugs, such as DNMT inhibitors, in combination with genetically engineered T cells.

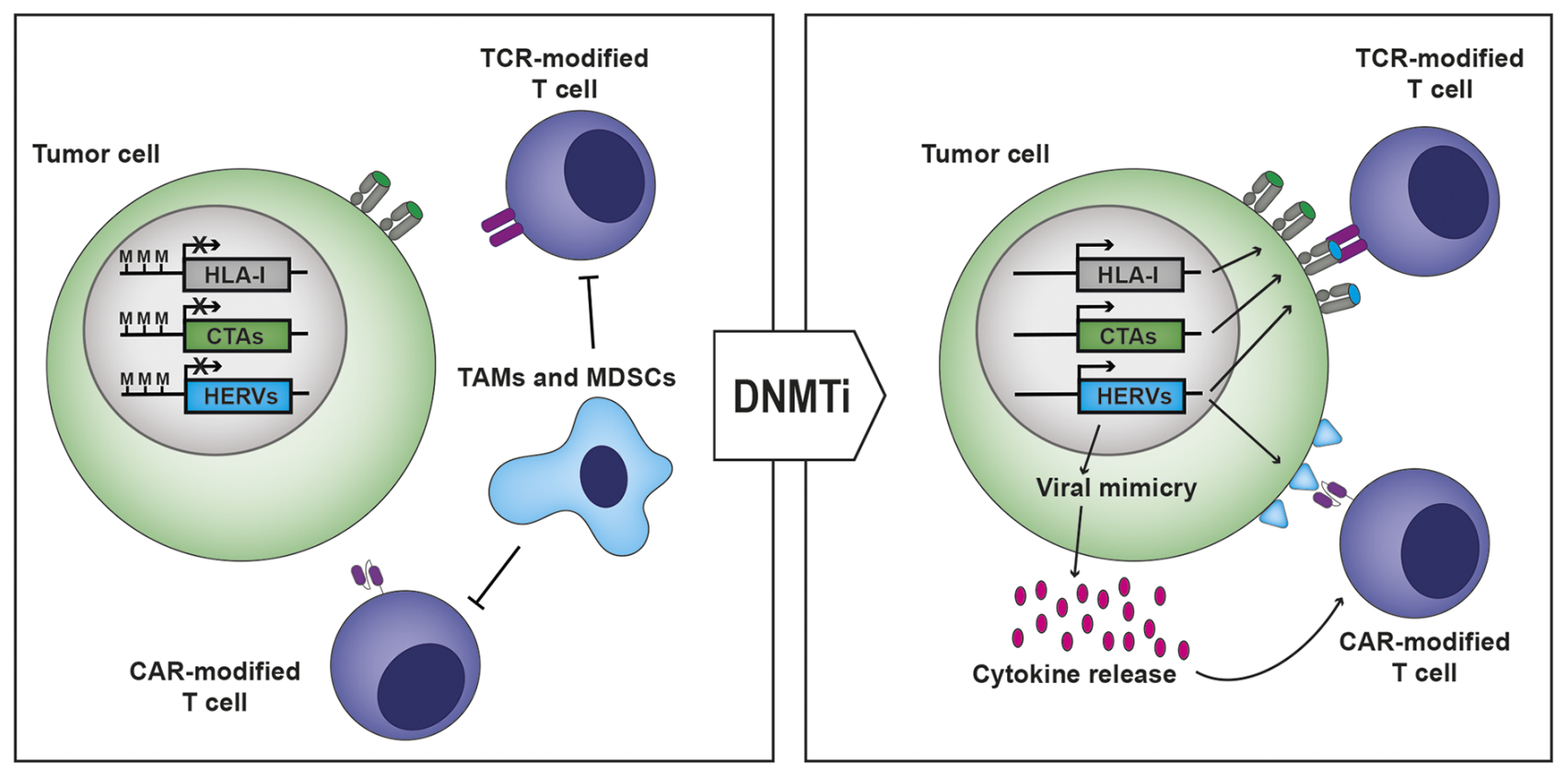


Table 1. Selected studies on the role of epigenetic modification of the tumor microenvironment

\begin{tabular}{|c|c|c|c|}
\hline $\begin{array}{l}\text { Compound } \\
\text { type }\end{array}$ & $\begin{array}{l}\text { Cancer type/cell } \\
\text { line model }\end{array}$ & $\begin{array}{l}\text { Effect on cancer cells or tumor } \\
\text { microenvironment }\end{array}$ & Reference \\
\hline DNMTi & $\begin{array}{l}\text { Ovarian cancer } \\
\text { xenograft }\end{array}$ & $\begin{array}{l}\text { Increased expression of CTA and HLA } \\
\text { I expression }\end{array}$ & (29) \\
\hline DNMTi & $\begin{array}{l}\text { Prostate cancer cell } \\
\text { lines }\end{array}$ & Increased expression of CTA & (30) \\
\hline $\begin{array}{l}\text { DNMTi } \\
\text { HDACi }\end{array}$ & Multiple cell lines & Increased expression of CTA & (34) \\
\hline $\begin{array}{l}\text { DNMTi } \\
\text { HDACi }\end{array}$ & $\begin{array}{l}\text { Breast cancer } \\
\text { patient tumors }\end{array}$ & Increased expression of HLA I & (44) \\
\hline DNMTi & $\begin{array}{l}\text { Ovarian cancer cell } \\
\text { lines }\end{array}$ & $\begin{array}{l}\text { Increased expression of HERVs and } \\
\text { type I IFN signaling }\end{array}$ & (45) \\
\hline DNMTi & $\begin{array}{l}\text { Colorectal cancer } \\
\text { cell lines }\end{array}$ & $\begin{array}{l}\text { Increased expression of HERVs and } \\
\text { type III IFN signaling }\end{array}$ & (46) \\
\hline DNMTi & $\begin{array}{l}\text { Multiple patient } \\
\text { tumors }\end{array}$ & Activation of IFN signaling & (47) \\
\hline $\begin{array}{l}\text { DNMTi } \\
\text { HDACi }\end{array}$ & $\begin{array}{l}\text { Ovarian cancer } \\
\text { mouse model }\end{array}$ & $\begin{array}{l}\text { Activation of IFN signaling, increase } \\
\text { CD8+ TILs, increased tumor } \\
\text { infiltrating NK cells, reduced TAMs } \\
\text { and tumor infiltrating MDSCs }\end{array}$ & (48) \\
\hline $\begin{array}{l}\text { DNMTi } \\
\text { HDACi }\end{array}$ & $\begin{array}{ll}\text { Syngeneic } & \text { breast } \\
\text { cancer } & \text { mouse } \\
\text { models } & \end{array}$ & Reduced tumor infiltrating MDSCs & (50) \\
\hline $\mathrm{EZH} 2 \mathrm{i}$ & $\begin{array}{l}\text { Syngeneic mouse } \\
\text { model and patient } \\
\text { tumors }\end{array}$ & Reduced activity of Tregs & (55) \\
\hline DNMTi & Leukemia & Depletion of MDSCs & (51) \\
\hline $\begin{array}{l}\text { HDACi } \\
\text { Bromodomain } \\
\text { inhibitor }\end{array}$ & $\begin{array}{lr}\text { Inducible lung } \\
\text { cancer mouse } \\
\text { model }\end{array}$ & Attenuation of MDSC function & $(56)$ \\
\hline
\end{tabular}


Table 2. Selected studies evaluating the combination of epigenetic inhibitors and ACT

\begin{tabular}{|c|c|c|c|}
\hline $\begin{array}{l}\text { Compound } \\
\text { type }\end{array}$ & $\begin{array}{l}\text { Cancer type/cell } \\
\text { line model }\end{array}$ & Effect on anti-tumor immunity & Reference \\
\hline DNMTi & $\begin{array}{l}\text { 4T1 breast cancer } \\
\text { syngeneic mice }\end{array}$ & $\begin{array}{l}\text { Increased expression of CTA P1A in } \\
\text { cancer cells and improved targeting } \\
\text { by P1A-specific T cells }\end{array}$ & (59) \\
\hline $\begin{array}{l}\text { DNMTi } \\
\text { HDACi }\end{array}$ & $\begin{array}{l}\text { Human breast } \\
\text { cancer cell lines }\end{array}$ & $\begin{array}{l}\text { Increased expression of CTA MAGE- } \\
\text { C2 in cancer cells and improved } \\
\text { targeting by MAGE-C2-specific T cells }\end{array}$ & (60) \\
\hline DNMTi & $\begin{array}{l}\text { Human colorectal } \\
\text { cancer cells }\end{array}$ & $\begin{array}{l}\text { Increased expression of CTA NY-ESO- } \\
1 \text { in cancer cells and improved } \\
\text { targeting by NY-ESO-1-specific T cells }\end{array}$ & (61) \\
\hline DNMTi & $\begin{array}{l}\text { Human glioma cell } \\
\text { xenograft model }\end{array}$ & $\begin{array}{l}\text { Increased expression of CTA NY-ESO- } \\
1 \text { in cancer cells and improved } \\
\text { targeting by NY-ESO-1-specific T cells }\end{array}$ & (62) \\
\hline DNMTi & $\begin{array}{l}\text { Human melanoma } \\
\text { cells }\end{array}$ & $\begin{array}{l}\text { Increased expression of PRAME in } \\
\text { cancer cells and improved targeting } \\
\text { by PRAME-specific T cells }\end{array}$ & (63) \\
\hline $\mathrm{HDACi}$ & $\begin{array}{l}\text { B16 melanoma } \\
\text { syngeneic mice }\end{array}$ & $\begin{array}{l}\text { Increased expression of } \mathrm{MHC} \text { and } \\
\text { CTA gp100 in cancer cells and } \\
\text { improved targeting by gp } 100 \text {-specific } \\
\text { T cells } \\
\text { Increase functional activity of T cells }\end{array}$ & (64) \\
\hline $\mathrm{EZH} 2 \mathrm{i}$ & $\begin{array}{l}\text { Ewing sarcoma cell } \\
\text { lines }\end{array}$ & $\begin{array}{l}\text { Increased production of } \mathrm{G}_{\mathrm{D} 2} \text { in cancer } \\
\text { cells and improved targeting by } \mathrm{G}_{\mathrm{D} 2^{-}} \\
\text {specific CAR T cells }\end{array}$ & (65) \\
\hline
\end{tabular}

